\title{
Correction to: Arduino-based low-cost electrical load tracking system with a long-range mesh network
}

\author{
Xinlin Wang ${ }^{1} \cdot$ Bora $\mathrm{Ha}^{1}$ - Frank Andrew Manongi ${ }^{1}$ - Woo-Kyun Jung ${ }^{1}$. \\ Yusufu Abeid Chande Jande ${ }^{2,3} \cdot$ Sung-Hoon Ahn ${ }^{1,4} \mathbb{C}_{\overparen{C}}$
}

Published online: 28 December 2020

(C) Shanghai University and Springer-Verlag GmbH Germany, part of Springer Nature 2020

\section{Correction to:}

Adv. Manuf.

https://doi.org/10.1007/s40436-020-00310-5

In the original publication the first author name is published incorrectly as "Xin-Lin Wang". The correct author name should be read as "Xinlin Wang".

Also, the correct fund note in the acknowledgement section should be "This research was supported in part by the International S\&T Cooperation Program through the National Research Foundation of Korea (NRF) funded by the Ministry of Science, ICT \& Future Planning (MSIP) (Grant No. NRF-2017K1A3A9A04013801), and by the Basic Research Lab Program through NRF funded by the MSIT (Grant No. 2018R1A4A1059976)".

The correct author name and correct fund note is available in this correction.

The original article can be found online at https:// doi.org/10.1007/s40436-020-00310-5.

Sung-Hoon Ahn

ahnsh@snu.ac.kr

1 Department of Mechanical and Aerospace Engineering, Seoul National University, Seoul, South Korea

2 School of Materials Energy Water and Environment and Environmental Sciences, Nelson Mandela African Institution of Science and Technology, Arusha, Tanzania

3 Water Infrastructure and Sustainable Energy Futures Centre, Nelson Mandela African Institution of Science and Technology, Arusha, Tanzania

4 Institute of Advanced Machinery and Design, Seoul National University, Seoul, South Korea 